\title{
Pesticide-contaminated feeds in integrated grass carp aquaculture: toxicology and bioaccumulation
}

\author{
J. Pucher ${ }^{1, *}$, T. Gut ${ }^{2}$, R. Mayrhofer ${ }^{3}$, M. El-Matbouli ${ }^{3}$, P. H. Viet ${ }^{4}$, N. T. Ngoc $^{4}$, \\ M. Lamers ${ }^{2}$, T. Streck ${ }^{2}$, U. Focken ${ }^{5}$ \\ ${ }^{1}$ Life Science Center, and ${ }^{2}$ Institute of Soil Science and Land Evaluation, Biogeophysics, University of Hohenheim, \\ 70599 Stuttgart, Germany \\ ${ }^{3}$ Clinical Division of Fish Medicine, University of Veterinary Medicine, 1210 Vienna, Austria \\ ${ }^{4}$ Research Center for Environmental Technology and Sustainable Development, Hanoi University of Science, Hanoi, Vietnam \\ ${ }^{5}$ Thünen-Institute of Fisheries Ecology, Federal Research Institute for Rural Areas, Forestry and Fisheries, \\ 22926 Ahrensburg, Germany
}

\begin{abstract}
Effects of dissolved pesticides on fish are widely described, but little is known about effects of pesticide-contaminated feeds taken up orally by fish. In integrated farms, pesticides used on crops may affect grass carp that feed on plants from these fields. In northern Vietnam, grass carp suffer seasonal mass mortalities which may be caused by pesticide-contaminated plants. To test effects of pesticide-contaminated feeds on health and bioaccumulation in grass carp, a net-cage trial was conducted with 5 differently contaminated grasses. Grass was spiked with 2 levels of trichlorfon/fenitrothion and fenobucarb. Unspiked grass was used as a control. Fish were fed at a daily rate of $20 \%$ of body mass for $10 \mathrm{~d}$. The concentrations of fenitrothion and fenobucarb in pond water increased over time. Effects on fish mortality were not found. Fenobucarb in feed showed the strongest effects on fish by lowering feed uptake, deforming the liver, increasing blood glucose and reducing cholinesterase activity in blood serum, depending on feed uptake. Fenobucarb showed increased levels in flesh in all treatments, suggesting bioconcentration. Trichlorfon and fenitrothion did not significantly affect feed uptake but showed concentration-dependent reduction of cholinesterase activity and liver changes. Fenitrothion showed bioaccumulation in flesh which was dependant on feed uptake, whereas trichlorfon was only detected in very low concentrations in all treatments. Pesticide levels were all detected below the maximum residue levels in food. The pesticide-contaminated feeds tested did not cause mortality in grass carp but were associated with negative physiological responses and may increase susceptibility to diseases.
\end{abstract}

KEY WORDS: Organophosphate pesticide Carbamate $\cdot$ Contaminated feeds Cholinesterase ChE $\cdot$ Risk assessment $\cdot$ Grass carp $\cdot$ Ctenopharyngodon idella $\cdot$ Fish farming

\section{INTRODUCTION}

Mountainous areas of northwest Vietnam have a long tradition of rice and fish culture. Typically, rice paddies and fish ponds are located side by side, with irrigation water flowing from rice paddies to fish ponds and vice versa. To increase yields, rice paddy management in this region includes the use of highquality seeds and chemical fertilizers as well as herbicides, insecticides, rodenticides and fungicides. Pesticides are typically applied 2 or 3 times per rice cultivation period. Most farmers apply pesticides at the same time, following the advice of the governmental extension service, which is communicated via 
radio and local loud speakers. While rice paddy culture has changed significantly and has become an intensive production system over the past decade, aquaculture management is still performed traditionally.

In this study, we focussed on 3 pesticides (trichlorfon, fenitrothion, fenobucarb; Table 1) that have often been applied in northern Vietnam. Trichlorfon and fenitrothion are organophosphate (OP) pesticides, whereas fenobucarb is a carbamate. All 3 substances are non-specific insecticides. Their mode of action is non-systemic with contact and stomach action. Their toxic effect is based on inhibition of cholinesterase (ChE) by binding to the esteratic site of the enzyme. $\mathrm{ChE}$ has a crucial function in all vertebrates; it hydrolyses acetylcholine, a neurotransmitter in the central and peripheral nervous system that transmits nerve signals across cholinergic synapses and is afterwards hydrolysed by acetyl- or butyryl-ChE (AChE or $\mathrm{BChE}$ ). If this process is interrupted by inhibiting the $\mathrm{ChE}$, the result is an accumulation of acetylcholine in the synapses and thus overstimulation of postsynaptic cholinergic receptors (Pope 1999), leading to rapid twitching of voluntary muscles followed by paralysis (Fulton \& Key 2001). The inhibition of ChE by binding OP pesticides is irreversible, and recovery depends on new enzyme synthesis, whereas carbamated enzymes can slowly recover (Sturm et al. 2000). This mechanism is so specific that it has been widely accepted as a bioindicator of exposure to OP and carbamate insecticides. More specifically, numerous studies have investigated $\mathrm{ChE}$ inhibition in fish species related to exposure to dissolved pesticides in surrounding water (Weiss 1961, Gruber \& Munn 1998, Chuiko 2000, Kirby et al. 2000, Sturm et al. 2000, Fulton \& Key 2001, Aker et al. 2008, Halappa \& David 2009, Kumar et al. 2011).

While pesticide contamination via water inflow to ponds has been studied elsewhere (e.g. Lamers et al.

Table 1. Properties of applied pesticides (http://sitem.herts. ac.uk/aeru/footprint/index2.htm). $K_{\mathrm{ow}}$ : octanol-water partition coefficient; $\mathrm{LC}_{50}$ : lethal concentration; NOEC: no observed effects concentration

\begin{tabular}{|lcccc|}
\hline Pesticide & $\begin{array}{c}\text { Water } \\
\text { solubility } \\
\left(\mathrm{mg} \mathrm{l}^{-1}\right)\end{array}$ & $\begin{array}{c}\text { Log } \\
K_{\mathrm{ow}}\end{array}$ & $\begin{array}{c}\text { Acute } 96 \mathrm{~h} \\
\mathrm{LC}_{50} \text { to fish } \\
\left(\mathrm{mg} \mathrm{l}^{-1}\right)\end{array}$ & $\begin{array}{c}\text { Chronic } \\
\text { 21 d NOEC } \\
\left(\mathrm{mg} \mathrm{l}^{-1}\right)\end{array}$ \\
\hline Trichlorfon & 120000 & 0.43 & $0.7^{\mathrm{a}}$ & - \\
Fenitrothion & 19 & 3.32 & $1.3^{\mathrm{a}}$ & $0.088^{\mathrm{a}}$ \\
Fenobucarb & 420 & 2.78 & $1.7^{\mathrm{b}}$ & $0.2^{\mathrm{c}}$ \\
a To rainbow trout Oncorhynchus mykiss & \\
'To common carp Cyprinus carpio & \\
' 14 d NOEC to C. Carpio (MEJ 2013) \\
\hline
\end{tabular}

2011, Anyusheva et al. 2012), the import pathway of pesticides to fish ponds via contaminated feeding material and their bioaccumulation in fish has not yet been considered in environmental studies, although it may also constitute a significant potential threat to integrated aquaculture.

The grass carp Ctenopharyngodon idella, a member of the family Cyprinidae, plays an important role in carp polyculture systems in Asia. Above a body length of about $25 \mathrm{~mm}$ (De Silva \& Weerakoon 1981), grass carp are capable of efficiently shredding plantderived material such as filamentous algae, emerged plants, grasses and leaves of trees and crops (Prowse 1971, Opuszynski 1972). Due to the low quality and digestibility of these feed resources, the amount ingested by grass carp may reach more than $100 \%$ of their body mass per day at water temperatures of 22 to $33^{\circ} \mathrm{C}$ (Opuszynski 1972). However, the actual amount varies greatly depending on water temperature (Opuszynski 1972, Cai \& Curtis 1990, Osborne \& Riddle 1999) and fish live mass (Osborne \& Riddle 1999). This macro-herbivore feeding habit allows farmers to grow grass carp with low financial input and to run a cash-generating pond aquaculture by feeding agricultural by-products.

For more than a decade, the populations of grass carp in the uplands and lowlands of northern Vietnam have been suffering from high mortality rates, usually in the rainy season from March to November (Van et al. 2002, Steinbronn 2009, Pucher et al. 2013). Diseased fish show typical symptoms such as haemorrhagic changes and ulcers on the skin, darkening or bleaching of the skin, loss of scales, haemorrhagic intestines, necrosis of the gills, exophthalmia or enophthalmia and erratic swimming behaviour (Van et al. 2002, Steinbronn 2009, Pucher et al. 2013). Mass mortalities of grass carp are attributed to a multi-factorial disease primarily caused by bacterial agents and may be triggered by unsuitable environmental factors, such as poor water quality, limited oxygen supply, poor feed bases and chronic or acute exposure to pesticides dissolved in water or included in feeds (Van et al. 2002, Steinbronn 2009, Anyusheva et al. 2012, Pucher et al. 2013).

In mountainous northern Vietnam, leaves of maize, banana, cassava and bamboo as well as weeds, grasses, human wastes and animal manure are commonly applied to ponds (Luu 2001, Steinbronn 2009). On a dry matter basis, $17 \pm 6 \%$ (mean $\pm \mathrm{SD}$ ) of all applied feed and fertilizer inputs were reported to originate from rice paddies and dykes, and the fresh matter amounted to $22.3 \pm 10.7 \mathrm{t} \mathrm{ha}^{-1}$ pond $^{-1} \mathrm{yr}^{-1}$ (Steinbronn 2009). These feed resources originating 
from rice paddies are especially available in the hot rainy season when rice is produced and include mixed weeds, water hyacinths and rice plants uprooted while thinning. Farmers have stated that they use feed resources from their own paddies and dikes or from collective feed resources (e.g. channels, rivers), which are potentially contaminated by pesticides (Steinbronn 2009).

Pesticides in food are differently degradable by cooking at degradation temperatures above (e.g. fenitrothion), below or around $100^{\circ} \mathrm{C}$ (e.g. fenobucarb, trichlorfon; http://sitem.herts.ac.uk/aeru/footprint/ index2.htm). In northern Vietnam, fish is often consumed raw (Kino et al. 1998, Steinbronn 2009, Phan et al. 2011). In Nam Dinh province, for example, $78 \%$ of persons interviewed stated that they eat raw fish (Nguyen \& Thanh 2011). In the research area, raw or slightly acid marinated filets of silver carp and grass carp are combined with cut leaves to make a traditional salad. Consumers of raw fish run the risk of infection by parasites such as Chlonorchis sinensis or fishborne zoonotic trematodes (Kino et al. 1998, Phan et al. 2010, 2011) or ingestion of pesticides which have accumulated in vegetables and fish (Hoai et al. 2011).

The aims of the present study were to investigate (1) whether pesticide-contaminated feed applied for a limited period of time $(10 \mathrm{~d}$, resembling the pesticide application practices of local farmers) leads to increased mortality or morbidity that has a measurable negative health effects in fish, and (2) whether pesticides taken up by fish via contaminated feed during a pesticide application campaign accumulate in fish flesh and thereby pose a potential threat to human health.

\section{MATERIALS AND METHODS}

\section{Experimental setup}

In summer 2010, a survey of 145 small-scale farmers was performed in Chieng Khoi commune, Yen Chau district, Son La province, northern Vietnam. The sizes of paddy fields and the kind as well as the amount of pesticides applied were recorded and used to calculate the amounts of individual pesticides per application and per unit of paddy area. The 2 commonly used pesticide products Ofatox (trichlorfon and fenitrothion) and NIBAS (fenobucarb) were selected for this study.

In 10 replicates, the biomass of grass per unit area of paddy dike was determined by cutting all biomass above the ground into defined areas of 5 rice paddy dikes. Under the assumption that the same amounts of pesticides are applied to the rice paddy and the paddy dike, we estimated the amounts of active ingredients (AIs) per $\mathrm{kg}$ fresh weight of grass grown on the paddy dike. These amounts were most likely to be found in grass collected by farmers to feed their carp and were called 'average farm dose' (AFD), equalling $65 \mathrm{mg}$ each of trichlorfon and fenitrothion $\mathrm{kg}^{-1}$ fresh weight of grass in paddy areas sprayed with Ofatox and $113 \mathrm{mg}$ fenobucarb $\mathrm{kg}^{-1}$ fresh weight of grass in paddy areas sprayed with NIBAS.

A total of $30 \mathrm{~kg}$ of uncontaminated grass was collected for the fish trial. Four aliquots of fresh grass were treated with Ofatox or NIBAS at AFD concentrations of trichlorfon + fenitrothion (Treatment A) and fenobucarb (Treatment D) and at doubled AFD concentrations (Treatments B and E, respectively). A control aliquot was treated only with water (Treatment $\mathrm{C}$ ). The levels of pesticide in the grass in each of the 5 treatments are given in Table 2 .

The pesticides were applied to the grass aliquots using aerosol cans. For each pesticide product and the control, a separate aerosol can was used. Low pesticide concentrations were sprayed first. For spraying, the total amount of each grass aliquot was spread on a plastic sheet $(2 \times 3 \mathrm{~m})$ lying on the ground. The respective amount of Ofatox or NIBAS was dissolved in $500 \mathrm{ml}$ of water and sprayed onto the grass aliquot under temporary mixing of the grass to ensure a homogenous inoculation. After inoculation, the pesticide solution was left to soak in for about $30 \mathrm{~min}$. The inoculated grass was then weighed out in daily feeding portions equivalent to $20 \%$ of the total body mass of all grass carp in each net cage. These feed portions were stored at $-18^{\circ} \mathrm{C}$ and defrosted $1 \mathrm{~h}$ before feeding.

Twenty net cages $(1.5 \times 1.5 \times 2 \mathrm{~m})$ were installed in a pond (depth $1.2 \mathrm{~m}$, in Sap Vat village, Yen Chau district) to assure the same environmental conditions

Table 2. Concentrations of active ingredients in fresh matter of grass fed to grass carp. AFD: average farm dose

\begin{tabular}{|lccc|}
\hline $\begin{array}{l}\text { Treat- } \\
\text { ment }\end{array}$ & $\begin{array}{c}\text { Active } \\
\text { ingredient(s) }\end{array}$ & $\begin{array}{c}\text { Concentration } \\
\left(\mathrm{mg} \mathrm{kg}^{-1}\right)\end{array}$ & $\begin{array}{c}\text { Contamination } \\
\text { level }\end{array}$ \\
\hline A & $\begin{array}{c}\text { Trichlorfon \& } \\
\text { fenitrothion }\end{array}$ & 65 & AFD \\
B & $\begin{array}{c}\text { Trichlorfon \& } \\
\text { fenitrothion }\end{array}$ & 130 & Doubled AFD \\
C & None & 0 & Negative control \\
D & Fenobucarb & 113 & AFD \\
E & Fenobucarb & 226 & Doubled AFD \\
\hline
\end{tabular}


in all replicates. Each cage rested at the bottom of the pond and was covered with a net over the top to prevent the fish from jumping out. Each cage was stocked with 3 grass carp (1 yr old; $171 \pm 33$ g body mass, $25.4 \pm 1.8 \mathrm{~cm}$ total body length, $\mathrm{n}=60$, mean \pm $\mathrm{SD}$ ) taken from a neighbouring pond, which had been stocked with a single batch of grass carp fingerlings from the hatchery in Son La city. The treatments were distributed randomly among the cages. In 4 replicates, the groups of grass carp were offered the 5 trial feeds at a level of $20 \%$ of body mass per day for a period of $10 \mathrm{~d}$ from 5 to 14 November 2011. The grass used as feed was confined to the net cages and could not contaminate other replicates. We checked daily to determine whether any fish had died. After the final harvest of fish on Day 10, the uneaten grass in the cages was weighed to estimate the percentage of feed uptake.

\section{Sampling and analysis}

Mixed-grab water samples were taken on Days 0, 5 and 10 at 3 positions in the pond and were analysed for water-soluble pesticide exposure and nitrogen compounds. Temperature, oxygen concentration and $\mathrm{pH}$ were constantly monitored using a multi-electrode data logger in situ (Troll 9500). On Day 0, 4 groups of 3 grass carp, and on Day 10, all grass carp from each net cage were killed, scaled, filleted and freeze dried to determine pesticide concentrations in the flesh. The percentage of intestinal filling was estimated as a second measure to evaluate feed uptake. Macroscopic liver alterations were evaluated for individual fish modified after Adams et al. (1993) and were were rated on a scale of 1 to 5 (1: no deformation; 2: slight deformation; 3: medium deformation; 4: strong deformation; 5 : very strong deformation). Blood samples were taken from all grass carp by heart puncture after they had been anaesthesised by percussion of the head and before they were killed by exsanguination. The blood was stored at $4^{\circ} \mathrm{C}$ for $10 \mathrm{~h}$ to allow clotting, before being centrifuged $(700 \times g$ for $10 \mathrm{~min})$ to separate blood clots and serum. Blood serum was stored at $-18^{\circ} \mathrm{C}$ and analysed for the concentration of $\mathrm{BChE}$ and glucose. Blood analysis of fish serum was performed on a fully selective auto-analyser for clinical chemistry (Cobas 6000/501c) and by the use of the ChE 2 Kit (Roche $\left.{ }^{\circledR}\right)$, according to the manufacturers' recommendations. The principle of this method is that ChE hydrolyses butyrylthiocholine to thiocholine and butyrate. Thiocholine reduces the yellow pig- ment hexacyanoferrate III to the nearly colourless hexacyanoferrate II. This decrease in colour intensity is measured at $700 / 415 \mathrm{~nm}$ wavelengths at $37^{\circ} \mathrm{C}$ and is directly proportional to the $\mathrm{ChE}$ activity. BChE was used as a biomarker because it has been reported to be more active compared to $\mathrm{AChE}$ if $\mathrm{BChE}$ is present in the serum of cyprinids (Chuiko 2000). For measurement of the glucose concentration in serum, the auto-analyser Cobas 6000/501c and a glucose HK Kit (Roche ${ }^{\circledR}$ ) were used according to the manufacturers' recommendations. In this method, hexokinase (HK) catalyses the phosphorylation of glucose by ATP to form glucose-6-phosphate and ADP. To measure the extent of this reaction, a second enzyme, glucose-6-phosphate dehydrogenase is used to catalyse oxidation of glucose-6-phosphate by NADP+ to form NADPH. The concentration of the NADPH formed is directly proportional to the glucose concentration, which is determined by measuring the increase in absorbance due to NADPH at $340 \mathrm{~nm}$.

For preparation of fish samples for pesticide analysis, fish flesh samples were ground with a grinder after the fish had been freeze-dried. Two grams of sample were weighed in a glass bottle. Surrogate diazinon-d10 and acetonitrile solvent were added to the bottle. The mixture was homogenized for $5 \mathrm{~min}$. The extract was filtered through a layer of anhydrous sodium sulphate and concentrated to $1 \mathrm{ml}$ by a rotary vacuum evaporator. The extracts were 'cleaned up' on 3 extraction columns (C18 [5 mg/3 ml, RP-18Merck K91203423], $\mathrm{NH}_{2}$ [2 g/12 ml, OROCHEM - SY $\mathrm{NH}_{2}$ ] and carbon [0.5 g/glass column, $20 \mathrm{~cm}$ length $\times$ $0.5 \mathrm{~cm}$ diameter]). Pesticides for analysis were eluted through the clean-up columns using 8,25 and $60 \mathrm{ml}$ of a solvent mixture of acetonitrile and toluene at a ratio of 3:1 (v/v). The eluate was concentrated to $1 \mathrm{ml}$. After adding $10 \mathrm{ml}$ of a solvent mixture of hexane and acetone $(1: 1 \mathrm{v} / \mathrm{v})$ and the internal standard chrysene-d12, the extract was again concentrated to $1 \mathrm{ml}$ using a stream of nitrogen gas. For preparation of grass samples for pesticide analysis, dried grass samples were ground with a grinder. One gram of sample was weighed into a polypropylene tube. Surrogate diazinon-d10 and acetonitrile solvent were added to the tube, and the sample was homogenized for $1 \mathrm{~min}$. After adding $4 \mathrm{~g} \mathrm{MgSO}_{4}$ and $1 \mathrm{~g} \mathrm{NaCl}$, the sample tube was shaken well for $1 \mathrm{~min}$ and centrifuged $(400 \times g)$ for $5 \mathrm{~min}$. Half of the sample extract was concentrated by a rotary vacuum evaporator. The extract was cleaned up on the following columns: a carbon column $(0.5 \mathrm{~g} /$ column, $20 \mathrm{~cm}$ length $\times 0.5 \mathrm{~cm}$ diameter), a Florisil cartridge $(1 \mathrm{~g} / 6 \mathrm{ml}$, Merck 
K93101027) and an $\mathrm{NH}_{2}$ cartridge $(2 \mathrm{~g} / 12 \mathrm{ml}$, OROCHEM - SY $\mathrm{NH}_{2}$ ). Pesticides for analysis were eluted through the clean-up columns in 60, 10 and 25 $\mathrm{ml}$ volumes of a solvent mixture of acetonitrile and toluene at a ratio of 3:1 (v/v), respectively. The eluate was concentrated to $1 \mathrm{ml}$. After adding $10 \mathrm{ml}$ of a solvent mixture of hexane and acetone $(1: 1 \mathrm{v} / \mathrm{v})$ and an internal standard (chrysene-d12), the extract was concentrated to $1 \mathrm{ml}$ again with a nitrogen gas stream.

Two $\mu \mathrm{l}$ of pond water and the final sample extracts of fish and grass were analysed by capillary gas chromatography-mass spectrometry using GCMSQP2010 (Shimadzu) equipped with a capillary column 'OV-5MS' $(30 \mathrm{~m} \times 0.25 \mathrm{~mm}$ i.d. $\times 0.25 \mu \mathrm{m}$ film thickness). The analytical conditions were as follows: injector temperature $250^{\circ} \mathrm{C}$, injection mode splitless: split ratio $1: 20$, ion source temperature $230^{\circ} \mathrm{C}$ and detector temperature $290^{\circ} \mathrm{C}$. The oven temperature was initially set to $100^{\circ} \mathrm{C}$ for $3 \mathrm{~min}$, raised to $300^{\circ} \mathrm{C}$ at a rate of $10^{\circ} \mathrm{C} \mathrm{min}^{-1}$, and held for $10 \mathrm{~min}$. Calibration was done with an internal standard (chrysen-d12). Diazinon-d10 was used as a surrogate standard. The specific ion mass $(\mathrm{m} / \mathrm{z})$ for quantification was 110 , 121 and 277 for trichlorfon, fenobucarb and fenitrothion, respectively. For confirmation, the specific ion mass was 109, 145 and 79 for trichlorfon, 150 for fenobucarb and 260 and 125 for fenitrothion. Analytical methods for fish and grass samples were applied according to Takatori et al. (2008). For fish and grass samples, the detection limits of pesticides were 1.28, 1.21 and $0.74 \mathrm{ng} \mathrm{g}^{-1}$ of sample dry matter (DM) for trichlorfon, fenobucarb and fenitrothion, respectively. Detection limits of water-dissolved pesticides were $0.01,0.005$ and $0.01 \mathrm{ng} \mathrm{l}^{-1}$ for trichlorfon, fenobucarb and fenitrothion, respectively.

\section{Statistical analysis}

Data sets were analysed by 1-way ANOVAs with time $0\left(\mathrm{~T}_{0}\right)$ and the 5 feeding treatments as factors. Data sets were tested for homogeneity by Levene's test. Data distributions were checked visually for normality. To meet the assumptions required before ANOVA could be rigorously applied, data sets were $\log$ or square root transformed if needed. Fisher's least significant difference (LDS) tests were performed as post hoc tests. Data sets (trichlorfon flesh accumulation, \% intestinal fill, grass eaten, liver alterations) which did not meet the assumptions necessary for ANOVAs or which were ordinal were analysed by using the non-parametric Kruskal-Wallis test followed by multiple comparison of mean ranks for all groups. All statistical analyses were performed using STATISTICA 8 (StatSoft ${ }^{\circledR}$ ).

\section{RESULTS}

\section{Water parameters}

The water quality parameters over the $10 \mathrm{~d}$ of the feeding trial were typical for an aquaculture pond. The $\mathrm{pH}$ of the pond water was 7.7 , the redox potential was $782 \pm 9 \mathrm{mV}$, and the average temperature was $24.9^{\circ} \mathrm{C}$, with minimum and maximum water temperatures of 24.2 and $25.8^{\circ} \mathrm{C}$. The dissolved oxygen was low with a mean $( \pm \mathrm{SD})$ of $2.7 \pm 1.7 \mathrm{mg} \mathrm{l}^{-1}$ and averaged daily minima of $0.9 \pm 0.8 \mathrm{mg} \mathrm{l}^{-1}$, which typically occurred at dawn. The turbidity was on average $35.8 \pm 10.2$ formazine nephelometric units (FNU). Concentrations of total ammonia nitrogen, nitrite nitrogen, nitrate nitrogen, orthophosphate phosphorus, total nitrogen and total phosphorus were $0.03 \pm 0.00,0.04 \pm 0.00,0.3 \pm 0.1,0.00 \pm 0.00,1.3$ \pm 0.2 and $0.1 \pm 0.0 \mathrm{mg} \mathrm{l}^{-1}$, respectively.

The concentrations of fenitrothion and fenobucarb in water increased from Day 0 to Day 10, whereas for trichlorfon a concentration of $0.31 \mathrm{\mu g} \mathrm{l}^{-1}$ was detected on Day 0, but on Days 5 and 10, the concentration was below the detection limit (Table 3 ). The concentrations of fenitrothion and fenobucarb increased by a factor of 3.5 and 3.9 from Day 0 to Day 10, respectively. Maximum concentrations reached 0.075 and $0.465 \mathrm{\mu g} \mathrm{l}^{-1}$ for fenitrothion and fenobucarb, respectively.

The grass fed to grass carp within the trial had a mean $( \pm \mathrm{SD})$ dry mass of $28.1 \pm 1.8 \%$ of fresh mass $(\mathrm{n}=6$; crude ash $15.6 \%$ of DM, crude lipid of $1.7 \%$ of DM). Table 4 summarizes the amounts of AIs fed daily per $g$ fresh mass of fish in the 5 treatment groups. No contamination of pesticide AIs was detected on grass which was fed to the control group of fish (Treatment C) (Table 4).

Control fish consumed all offered grass, which was confirmed by the feed uptake estimates shown in Table 5. When sprayed on the feed, trichlorfon and fenitrothion (treatments A and B) led to a reduction in

Table 3. Mean $( \pm \mathrm{SD})$ concentration $\left(\mu \mathrm{g} \mathrm{l}^{-1}\right)$ of dissolved active ingredients in pond water over the period of the feeding trial. nd: not detected

\begin{tabular}{|rccc|}
\hline Day & Trichlorfon & Fenitrothion & Fenobucarb \\
\hline 0 & $0.031 \pm 0.010$ & $0.021 \pm 0.003$ & $0.12 \pm 0.03$ \\
5 & nd & $0.058 \pm 0.006$ & $0.34 \pm 0.042$ \\
10 & nd & $0.075 \pm 0.001$ & $0.465 \pm 0.021$ \\
\hline
\end{tabular}


Table 4. Means $( \pm \mathrm{SD})$ of the amounts of active ingredients (AI, in $n g)$ offered daily on spiked grass per $g$ fresh mass of grass carp over the $10 \mathrm{~d}$ period of the feeding trial and AI accumulated (in ng) per $\mathrm{g}$ dry matter of flesh of grass carp fed before (time $0, \mathrm{~T}_{0}$ ) and after $10 \mathrm{~d}$ of feeding the contaminated grass. Cells with gray shading refer to the groups fed with the respective AI. Mean values of accumulated AI that do not share the same superscript(s) within a column differ significantly at $\mathrm{p} \leq$ 0.05. Mean values in columns without superscripts do not differ significantly

\begin{tabular}{|c|c|c|c|c|c|c|}
\hline \multirow[t]{2}{*}{ Treatment } & \multicolumn{2}{|c|}{ Trichlorfon $\longrightarrow$} & \multicolumn{2}{|c|}{ - Fenitrothion -} & \multicolumn{2}{|c|}{ Fenobucarb } \\
\hline & AI fed & $\begin{array}{l}\text { AI accumulated } \\
\text { in flesh }\end{array}$ & AI fed & $\begin{array}{l}\text { AI accumulated } \\
\text { in flesh }\end{array}$ & AI fed & $\begin{array}{c}\text { AI accumulated } \\
\text { in flesh }\end{array}$ \\
\hline $\mathrm{T}_{0}$ & & $0.0 \pm 0.0$ & & $3.9 \pm 3.5^{z}$ & & $3.4 \pm 0.9^{\mathrm{z}}$ \\
\hline $\mathrm{A}$ & $2417 \pm 157$ & $0.0 \pm 0.0$ & $2205 \pm 144$ & $103.7 \pm 29.0^{y}$ & $18 \pm 1$ & $12.5 \pm 6.6^{\mathrm{y}}$ \\
\hline $\mathrm{B}$ & $3667 \pm 239$ & $1.1 \pm 2.2$ & $5463 \pm 356$ & $156.3 \pm 23.6^{y}$ & $31 \pm 2$ & $9.0 \pm 3.7^{y}$ \\
\hline $\mathrm{C}$ & $0 \pm 0$ & $6.0 \pm 7.0$ & $0 \pm 0$ & $8.7 \pm 5.8^{z}$ & $0 \pm 0$ & $10.1 \pm 2.8^{y}$ \\
\hline $\mathrm{D}$ & $9 \pm 1$ & $0.0 \pm 0.0$ & $7 \pm 0$ & $10.9 \pm 2.9^{z}$ & $16764 \pm 1092$ & $13.9 \pm 4.6^{\mathrm{y}}$ \\
\hline $\mathrm{E}$ & $7 \pm 0$ & $1.2 \pm 2.2$ & $26 \pm 2$ & $10.9 \pm 8.9^{\mathrm{z}}$ & $22566 \pm 1469$ & $11.5 \pm 1.0^{\mathrm{y}}$ \\
\hline
\end{tabular}

Table 5. Mean $( \pm \mathrm{SD})$ feed uptake estimates and macroscopic alterations of grass carp liver on Day 10 of the trial and concentration of blood serum glucose and butyrylcholinesterase (BChE) activity in blood serum of grass carp before (time 0 , $\mathrm{T}_{0}$ ) and after $10 \mathrm{~d}$ of feeding on grass treated with pesticides. Within columns, mean values that do not share the same superscript(s) differ significantly at $p \leq$ 0.05. Macroscopic alterations of liver were assessed on a scale from 1 to 5 (1: no deformation; 2: slight deformation; 3: medium deformation; 4: strong deformation; 5: very strong deformation)

\begin{tabular}{|lccccc|}
\hline Treatment & $\begin{array}{c}\text { Intestinal } \\
\text { fill }(\%)\end{array}$ & $\begin{array}{c}\text { Grass eaten } \\
\text { (\% of daily } \\
\text { amount offered) }\end{array}$ & $\begin{array}{c}\text { Macroscopic } \\
\text { liver defor- } \\
\text { mation scale }\end{array}$ & $\begin{array}{c}\text { Glucose } \\
(\mathrm{mg} \mathrm{dl})^{-1} \\
\text { serum })\end{array}$ & $\begin{array}{c}\text { BChE } \\
\left(\mathrm{U} \mathrm{l}^{-1}\right. \\
\text { serum })\end{array}$ \\
\hline $\mathrm{T}_{0}$ & - & - & - & $115 \pm 13^{\mathrm{z}}$ & $93 \pm 33^{\mathrm{zx}}$ \\
$\mathrm{A}$ & $70 \pm 44^{\mathrm{zx}}$ & $75 \pm 6^{\mathrm{zx}}$ & $1.0 \pm 0.0^{\mathrm{z}}$ & $101 \pm 19^{\mathrm{zx}}$ & $84 \pm 50^{\mathrm{zxt}}$ \\
$\mathrm{B}$ & $72 \pm 42^{\mathrm{zx}}$ & $65 \pm 13^{\mathrm{zx}}$ & $2.3 \pm 0.9^{\mathrm{zx}}$ & $96 \pm 19^{\mathrm{yxw}}$ & $48 \pm 17^{\mathrm{ywv}}$ \\
$\mathrm{C}$ & $100 \pm 0^{\mathrm{z}}$ & $100 \pm 0^{\mathrm{z}}$ & $1.0 \pm 0.0^{\mathrm{z}}$ & $91 \pm 11^{\mathrm{y}}$ & $83 \pm 22^{\mathrm{zxu}}$ \\
$\mathrm{D}$ & $36 \pm 40^{\mathrm{yx}}$ & $40 \pm 8^{\mathrm{yx}}$ & $4.1 \pm 0.2^{\mathrm{yx}}$ & $107 \pm 22^{\mathrm{zw}}$ & $55 \pm 20^{\mathrm{yvt}}$ \\
$\mathrm{E}$ & $10 \pm 0^{\mathrm{yx}}$ & $23 \pm 15^{\mathrm{yx}}$ & $5.0 \pm 0.0^{\mathrm{y}}$ & $117 \pm 9^{\mathrm{z}}$ & $63 \pm 25^{\mathrm{zxv}}$ \\
\hline
\end{tabular}

feed uptake compared to the control and accounted for about $70 \%$ of offered feed. Fenobucarb in concentrations found in AFD (Treatment D) reduced the feed uptake to about $40 \%$ of offered feed and to about $20 \%$ under the doubled concentration.

\section{Health effects}

Although over the $10 \mathrm{~d}$ of the feeding experiment none of the fish died, various other health effects were observed. BChE was detected in blood serum of all grass carp. BChE activity in the blood serum of grass carp was lowered when the fish were offered feed treated with pesticides (Table 5), especially high concentrations of trichlorfon and fenitrothion (Treatment B). Compared to the control group, BChE activity decreased by $43 \%$ in Treatment B, by $34 \%$ in Treatment D and by $24 \%$ in Treatment E. In Treatment $\mathrm{A}$, activity increased slightly by $1 \%$.
The blood serum glucose concentration was significantly lower in fish fed unspiked grass (Treatment C) than in fish that were sampled before the trial started (Table 5). Within the trial, fish in all treatments had higher blood serum glucose levels than the controls, but fish that were treated with fenobucarb (Treatments D and E) had higher levels than those dosed with trichlorfon + fenitrothion (Treatments A and B).

Macroscopic symptoms of disease, such as haemorrhagic changes and ulcers on the skin, darkening or bleaching of the skin, loss of scales, necrosis of the gills, exophthalmia, enophthalmia and erratic swimming behaviour, were not apparent in any of the grass carp in this trial. Fish were examined for internal macroscopic changes, whereupon we found that the treatments had profound and different effects on the colour of the liver (Table 5). Fish fed grass with no AIs (Treatment C) had red livers. Feeding of trichlorfon and fenitrothion at the concentration of AFD (Treatment A) did not affect the colour of the liver, but double the AFD amount resulted in a yellow colouration. The application of fenobucarb had a profound effect on liver colour, which changed from intense yellow to brown with increasing concentration in the grass offered (Treatments D and E).

\section{Pesticide concentration in flesh}

The fresh fish flesh sampled for the pesticide accumulation measurements accounted for $34.9 \pm 2.1 \%$ 
(mean $\pm \mathrm{SD}$ ) of the sampled grass carp. These samples had a mean dry mass of $20.9 \pm 0.8 \%$ of the fresh mass. The flesh of experimental fish sampled at $T_{0}$ showed low accumulation of all 3 tested AIs. Trichlorfon offered on grass did not accumulate in the flesh (Table 4), even though most of the offered grass was consumed by the fish (Table 5). Trichlorfon was only detected in 1 fish in 2 other treatments each.

Fenitrothion fed to grass carp accumulated significantly in the flesh over the $10 \mathrm{~d}$ of feeding and showed significantly higher accumulation compared to that in fish that were not fed grass spiked with fenitrothion (Table 4). Fenobucarb showed an increased accumulation in all fish, but the increase was statistically significant only in the flesh of fish which were offered grass spiked with the lower concentration of fenobucarb (Table 4). Offering grass spiked with higher concentrations of this AI did not increase the accumulation in flesh, as the grass was not accepted by grass carp (Table 4).

\section{DISCUSSION}

\section{Water parameters}

The water parameters of the experimental pond met the requirements for grass carp culture. The water temperature was in the optimal temperature range for intensive feeding of grass carp (Opuszynski 1972). In the morning, dissolved oxygen levels were recorded to be near the minimal tolerable level of $0.5 \mathrm{mg} \mathrm{l}^{-1}$ for grass carp (Froese \& Pauly 2013) which are typical in this region (Steinbronn 2009, Pucher et al. 2013) but did not visibly affect the health of the experimental grass carp.

In pond water, concentrations of fenitrothion and fenobucarb increased significantly during the study, whereas concentrations of trichlorfon could not be detected on Days 5 and 10. This finding is surprising, given that trichlorfon has by far the highest water solubility of the 3 tested substances. On the other hand, trichlorfon also quickly degrades to dichlorvos, which was not analysed. The increasing concentrations of fenitrothion peaked at $0.075 \mathrm{\mu g} \mathrm{l}^{-1}$ and of fenobucarb at $0.465 \mu \mathrm{g} \mathrm{l}^{-1}$. These results clearly indicate that a fraction of the pesticides spiked on the grass fed to the fish also dissolved in the water of the pond. The more soluble fenobucarb reached higher concentrations than the less soluble fenitrothion. In all cases, the concentration levels remained below the lethal concentration $\left(\mathrm{LC}_{50}\right)$ given in Table 1. However, fish in the control group
(Treatment C) showed some alterations of the measured parameters in comparison to fish before the treatments $\left(\mathrm{T}_{0}\right)$, thus indicating a contribution of waterborne pesticide exposure to the observed effects. Very limited information is available on pesticide effects on grass carp. The highest measured concentrations of fenitrothion and fenobucarb $(0.075$ and $0.465 \mathrm{\mu g} \mathrm{l}^{-1}$, respectively) were far below the no observed effects concentrations (NOECs) to Cyprinus carpio reported at 0.088 and $0.2 \mathrm{mg} \mathrm{l}^{-1}$, respectively (see Table 1). For trichlorfon, no NOEC was found in the literature. However, given the fact that trichlorfon was not found at concentrations above the detection limit $\left(0.01 \mathrm{ng} \mathrm{l}^{-1}\right)$ in the course of the experiment, no effect of trichlorfon is expected, but effects of its metabolite dichlorvos (not measured) cannot be excluded. However, NOECs are usually determined under controlled laboratory conditions without other stressors for the fish. Under pond conditions, health effects of pesticide concentrations could occur below the NOEC, due to coupled effects of a variety of stress factors. This is indicated by the predicted no effect concentration (PNEC), below which absolutely no effects would be expected. PNEC values are often considerably lower than the NOEC values. In case of fenitrothion, for instance, the PNEC is $0.00021 \mathrm{\mu g} \mathrm{l}^{-1}$ (vs. the NOEC of $0.088 \mathrm{mg} \mathrm{l}^{-1}$ ) and hence was exceeded by the observed concentration. However, in this trial, feedborne pesticide exposure effects were evaluated, not the potential waterborne pesticide exposure effects from dissolved pesticide concentrations carried into the pond via the treated feeding material. Therefore, all measured effects of all treatment groups were evaluated versus the control group and not versus $\mathrm{T}_{0}$.

\section{Health effects}

The type and amount of grass was fully accepted by grass carp, as the amount offered ( $20 \%$ of live weight per day) was consumed completely. Spiking the feeds with the 2 pesticide products had significant effects on the feed acceptance of grass carp. Trichlorfon and fenitrothion on the grass resulted, on average, in a slight reduction of feed uptake which was not concentration dependent. Fenobucarb on the grass resulted in a significantly reduced feed uptake of spiked grass which was concentration dependent. It is not known whether the refusal of pesticidespiked grass was caused by a decrease in palatability or by reduced appetite caused by negative effects of 
the AIs on the health of the fish. However, pesticides are known to reduce feed intake in fish (Kestemont \& Baras 2001).

The spiked feeds had feed-dependent effects on macroscopic liver colouration. In crucian carp, trichlorfon dissolved in ambient water had strong effects on hepatic pathways of lipid metabolism and increased lipid accumulation in the liver $(\mathrm{Xu}$ et al. 2012).

Little information has been published on macroscopic changes in the colour of fish livers. However, laboratory tests and field studies have demonstrated that fish exposed to pesticides show pathologic changes in the liver (Kumar \& Ansari 1986, Gill et al. 1988) and that OPs are reported to have negative effects on the antioxidant system of carp and therefore lead to 'oxidative stress' (Hai et al. 1997). This 'oxidative stress' has been found to be the cause of jaundice, which causes yellowish decolouration in the liver of yellowtails Seriola quinqueradiata (Sakai et al. 1998). Wolf \& Wolfe (2005) stated that a general macroscopic response of the fish liver to toxins is a darkening of the liver. This liver colouration is a strong indication of pathological damage to the organ. Liver changes affect fitness of fish (Rodrigues \& Fanta 1998).

BChE was detected in the blood serum of all grass carp. This makes grass carp a member of the family Cyprinidae in which BChE can be used as marker for pesticide treatment (Chuiko 2000). All treatments, including the control group Treatment $\mathrm{C}$, showed decreased BChE activity compared to fish sacrificed at $\mathrm{T}_{0}$. Fish in Treatment $\mathrm{C}$, which had been fed uncontaminated feed, showed a BChE activity decrease of $11 \%$. This effect is likely to be derived from pesticides dissolved in the water. However, the changes in BChE activity of treatment groups compared to the control group can be attributed to effects caused by the pesticide-spiked feeding material and therefore indicate that pesticide intake via feed plays an important role in addition to any effects due to dissolved compounds. The feeding of trichlorfon and fenitrothion at AFD levels (Treatment A) did not lead to any significant change in BChE activity compared to the control group and therefore seems to be tolerable for grass carp. However, the feeding of the same AI at double the AFD concentrations led to the highest BChE decrease of all treatments; the BChE activity was decreased by $43 \%$ compared to Treatment C. The feed acceptance of fish in Treatments A and B was comparable. Therefore, the level of BChE activity decrease seems to be concentration dependent. Both AIs of Treatments A and B are OP pesticides which lead to irreversible BChE inhibition (Sturm et al. 2000).

The decrease in BChE activity in fish from Treatments D and E was less distinct. Feeding of the AI fenobucarb at AFD levels (Treatment D) resulted in $34 \%$ reduced $\mathrm{BChE}$ activity compared to Treatment $\mathrm{C}$ (control). Feeding of the same AI at double the AFD concentrations led to a smaller reduction in BChE activity of $24 \%$ compared to Treatment C. This effect might be explained by the fact that fenobucarb seemed to have a strong effect on feed acceptance. Grass in Treatment E was less well accepted than that in Treatment D. Furthermore, macroscopic health effects indicated that fish from Treatment E were suffering stronger impacts on their vitality than fish from Treatment D. Thus, the fish from Treatment $\mathrm{E}$ incorporated less feeding material and therefore less fenobucarb than fish from Treatment D. Furthermore, fenobucarb is a carbamate insecticide, and its ChE inhibiting effects are to a certain degree reversible (Sturm et al. 2000). The recovery from ChE inhibition could have been expressed to different degrees in individual fish.

Overall, our findings are comparable to data in the current scientific literature. Gruber \& Munn (1998) reported that the mean whole-brain ChE activity of carp exposed to OP and carbamate insecticides was $34 \%$ less than that of carp from a lake that was not influenced by agricultural irrigation waters. A review on AChE inhibition in estuarine fish as an indicator of OP insecticide exposure (Fulton \& Key 2001) indicates that AChE inhibition levels of $50 \%$ can lead to sublethal effects on stamina and that AChE inhibition levels of $>70 \%$ are associated with mortality in most tested species. Concentration dependency of AChE inhibition was shown by Kumar et al. (2011), who reported that increasing levels of endosulphan in the water reduced the AChE activity in Nile tilapia.

Serum glucose levels are described as a general stress-indicating parameter in fish (Wedemeyer 1972). In this study, the pesticide-contaminated feeds affected the serum glucose significantly, with higher levels of glucose in the serum of fish fed pesticidetreated grass. No comparative data are available in the literature for the haematological response of fish to pesticide-contaminated feed. However, sub-lethal concentrations of pesticides in water increased blood glucose levels in fish showing an increased stress level (Chandrasekar \& Jayabalan 1993, Sweilum 2006, Kumar et al. 2011). The elevated glucose level in grass carp at $\mathrm{T}_{0}$ is most likely caused by the stress of handing and by the limited acclimatization time in net cages prior to the trial. 


\section{Pesticide concentration in flesh}

Among the 3 tested AIs, only fenitrothion showed a clearly feed-dependent accumulation in the fresh flesh with a bioaccumulation rate of about $1 \%$ and $0.6 \%$ (Treatments A and B) of the offered amount of AI over the feeding period. Fenitrothion concentrations increased in all fish compared to concentrations at $\mathrm{T}_{0}$. However, the fenitrothion concentration in fish of Treatment groups C, D and E increased only by a factor of 2 to $3 \times$ compared to $T_{0}$, whereas in the 2 groups which were fed fenitrothion (Treatments A and B), the increase was by a factor of $26 \times$ (Treatment A) and 40x (Treatment B). This very high increase in fish fed with fenitrothion-spiked grass compared to other groups must be caused by intake via feeding materials.

Trichlorfon and fenobucarb levels in fish flesh did not show treatment-dependent differences but increased significantly during the course of the feeding trial, which suggests that the concentration of these 2 pesticides dissolved in pond water is of more significance than the contamination of feed. These findings are in line with the physical properties of the 3 AIs and also with the results of pesticide concentrations in the water and feed acceptance by the experimental fish. The AI showing the highest food-dependent accumulation, fenitrothion, has the lowest water solubility and the highest log octanol-water partition coefficient $\left(K_{\mathrm{ow}}\right)$ and hence the highest potential for bioaccumulation. Therefore, we expected to find comparatively low concentrations of fenitrothion in the water but high bioaccumulation once it had been ingested by the fish via the feed. Fenobucarb on the other hand shows higher water solubility and a comparatively long aqueous degradation half-life time $\left(\mathrm{DT}_{50}\right)$. Therefore, higher concentrations of fenobucarb in water could be expected. Furthermore, fenobucarb-treated feed was much less acceptable to the fish than fenitrothion- and trichlorfon-treated feed. However, accumulation of trichlorfon did not follow the same pattern. Trichlorfon did not accumulate in the flesh of any of the treated groups. Only in fish of the control group (Treatment C) could any increase in trichlorfon concentration in fish flesh be observed. However, this high trichlorfon level in the control group was most likely an artefact as can be seen from the high standard deviation and the fact that in all other treatment groups, trichlorfon was below the detection level. Furthermore, although trichlorfon has the highest water solubility of all 3 tested AIs, it also has a very short aqueous $\mathrm{DT}_{50}$ half-life and is rapidly degraded to dichlorvos. Trichlorfon was not detected dissolved in the water on Days 5 and 10 and has a very low $K_{\mathrm{ow}}$ value of 0.43 . Considering these facts, significant bioaccumulation in fish flesh was not to be expected. However, measuring dichlorvos would be beneficial in future studies. Trichlorfon and fenobucarb were detected in fish flesh prior to the feeding trial in comparable amounts to those reported by Hoai et al. (2011), who performed a survey on pesticide contamination of food fish in northern Vietnam.

We can conclude that contamination of feeds with the AIs used in this study directly reduces fish production by reducing feed intake in the case of fenobucarb and by affecting fish health status in the case of all tested AIs, confirming that the intensification of rice farming is a threat to integrated aquaculture. Future studies on the effects of orally applied pesticides on fish health and production should focus on realistic scenarios in several ponds by including seasonal and spatial differences over the complete production cycle. For consumers of such fish, orally applied pesticides after a short period of $10 \mathrm{~d}$ pose little risk, as the levels of fenitrothion and trichlorfon in the flesh of grass carp before and after the trial were below the maximum residue levels (fenitrothion at $0.01 \mathrm{mg} \mathrm{kg}^{-1}$ fresh fish and trichlorfon at $0.1 \mathrm{mg} \mathrm{kg}^{-1}$ fresh fish) given by the European Commission for terrestrial animal products (EC 2005, aquatic animal products not listed). For example, taking the highest accumulation of fenitrothion under AFD conditions (Treatment A) after $10 \mathrm{~d}$ of feeding, a person weighing $50 \mathrm{~kg}$ would have to consume about $13.6 \mathrm{~kg}$ of grass carp filet in a day to reach even the minimum intake deemed to be harmful (acceptable daily intake) of $0.006 \mathrm{mg} \mathrm{kg}^{-1}$ body weight (WHO 2009). However, to evaluate the potential risk of consumers from accumulated pesticides in fish, a steady state pesticide accumulation assessment would be needed, taking into account the entire production cycle of fish for consumption.

Acknowledgements. This study was funded by the Deutsche Forschungsgemeinschaft (DFG) and was performed under the umbrella of the Uplands Program (SFB 564) in close collaboration between the University of Hohenheim (Germany) and the Hanoi University of Agriculture (Vietnam). Special thanks to P. Lawrence for language editing.

\section{LITERATURE CITED}

Adams SM, Brown AM, Goede RW (1993) A quantitative health assessment index for rapid evaluation of fish condition in the field. Trans Am Fish Soc 122:63-73

Aker WG, Hu X, Wang P, Hwang HM (2008) Comparing the relative toxicity of malathion and malaoxon in blue cat- 
fish Ictalurus furcatus. Environ Toxicol 23:548-554

Anyusheva M, Lamers M, La N, Nguyen VV, Streck T (2012) Fate of pesticides in combined paddy rice-fish pond farming systems in Northern Vietnam. J Environ Qual 41:515-525

Cai Z, Curtis LR (1990) Effects of diet and temperature on food consumption, growth rate and tissue fatty-acid composition of triploid grass carp. Aquaculture 88:313-327

Chandrasekar S, Jayabalan N (1993) Hematological responses of the common carp, Cyprinus carpio L. exposed to the pesticide endosulfan. Asian Fish Sci 6:331-340

Chuiko GM (2000) Comparative study of acetylcholinesterase and butyrylcholinesterase in brain and serum of several freshwater fish: specific activities and in vitro inhibition by DDVP, an organophosphorus pesticide. Comp Biochem Physiol C Toxicol Pharmacol 127:233-242

> De Silva SS, Weerakoon DEM (1981) Growth, food intake and evacuation rates of grass carp, Ctenopharyngodon idella fry. Aquaculture 25:67-76

EC (European Commission) (2005) EU pesticides database: pesticide EU- MRLs (maximum residue levels) based on the Regulation (EC) No 396/2005. European Parliament and of the Council. Available at http://ec.europa.eu/ sanco_pesticides/public/index.cfm (accessed on 20 February 2013)

Froese R, Pauly D (eds) (2013) FishBase. Species summary: Ctenopharyngodon idella (Valenciennes, 1844), Grass carp. www.fishbase.org/summary/Ctenopharyngodonidella.html (accessed on 8 January 2013)

Fulton MH, Key PB (2001) Acetylcholinesterase inhibition in estuarine fish and invertebrates as an indicator of organophosphorus insecticide exposure and effects. Environ Toxicol Chem 20:37-45

Gill TS, Pant JC, Pant J (1988) Gill, liver and kidney lesions associated with experimental exposures to carbaryl and dimethoate in the fish (Puntius conchonius Ham.). Bull Environ Contam Toxicol 41:71-78

- Gruber SJ, Munn MD (1998) Organophosphate and carbamate insecticides in agricultural waters and cholinesterase (ChE) inhibition in common carp (Cyprinus carpio). Arch Environ Contam Toxicol 35:391-396

- Hai DQ, Varga SI, Matkovics B (1997) Organophosphate effects on antioxidant system of carp (Cyprinus carpio) and catfish (Ictalurus nebulosus). Comp Biochem Physiol C Pharmacol Toxicol Endocrinol 117:83-88

- Halappa R, David M (2009) Behavioural responses of the freshwater fish, Cyprinus carpio (Linnaeus) following sublethal exposure to chlorpyrifos. Turk J Fish Aquat Sci 9:233-238

> Hoai PM, Sebesvari Z, Minh TB, Viet PH, Renaud FG (2011) Pesticide pollution in agricultural areas of northern Vietnam: case study in Hoang Liet and Minh Dai communes. Environ Pollut 159:3344-3350

Kestemont P, Baras E (2001) Environmental factors and feed intake: mechanisms and interaction. In: Houlihan D (ed) Food intake in fish. Blackwell Science, London, p 131-146

Kino H, Inaba H, Van De N, Van Chau L and others (1998) Epidemiology of clonorchiasis in Ninh Binh Province, Vietnam. Southeast Asian J Trop Med Public Health 29: 250-254

Kirby MF, Morris S, Hurst M, Kirby SJ, Neall P, Tylor T, Fagg A (2000) The use of cholinesterase activity in flounder (Platichthys flesus) muscle tissue as a biomarker of neurotoxic contamination in UK estuaries. Mar Pollut Bull 40: $780-791$
Kumar K, Ansari BA (1986) Malathion toxicity: effect on the liver of the fish Brachydanio rerio (Cyprinidae). Ecotoxicol Environ Saf 12:199-205

Kumar N, Prabhu PAJ, Pal AK, Remya S and others (2011) Anti-oxidative and immuno-hematological status of tilapia (Oreochromis mossambicus) during acute toxicity test of endosulfan. Pestic Biochem Physiol 99:45-52

Lamers M, Anyusheva M, La N, Nguyen VV, Streck T (2011) Pesticide pollution in surface- and groundwater by paddy rice cultivation: a case study from Northern Vietnam (short communication). CLEAN Soil Air Water 39: 356-361

Luu LT (2001) The VAC system in northern Viet Nam. In: Integrated agriculture-aquaculture. Fisheries Tech Pap 407. FAO, Rome, p 29-32

MEJ (Ministry of the Environment in Japan) (2013) Results of eco-toxicity tests of chemicals. Available at www.env. go.jp/chemi/sesaku/02e.pdf (accessed on 1 December 2013)

Nguyen VD, Thanh HL (2011) Human infections of fishborne trematodes in Vietnam: prevalence and molecular specific identification at an endemic commune in Nam Dinh province. Exp Parasitol 129:355-361

Opuszynski K (1972) Use of phytophagous fish to control aquatic plants. Aquaculture 1:61-74

Osborne JA, Riddle RD (1999) Feeding and growth rates for triploid grass carp as influenced by size and water temperature. J Freshw Ecol 14:41-45

> Phan VT, Ersbøll AK, Nguyen KV, Madsen H, Dalsgaard A (2010) Farm-level risk factors for fish-borne zoonotic trematode infection in integrated small-scale fish farms in northern Vietnam. PLoS Negl Trop Dis 4:e742

> Phan VT, Ersbøll AK, Do DT, Dalsgaard A (2011) Raw-fisheating behavior and fishborne zoonotic trematode infection in people of northern Vietnam. Foodborne Pathog Dis 8:255-260

Pope CN (1999) Organophosphorus pesticides: Do they all have the same mechanism of toxicity? J Toxicol Environ Health B 2:161-181

> Prowse GA (1971) Experimental criteria for studying grass carp feeding in relation to weed control. Prog Fish-Cult 33:128-131

Pucher J, Steinbronn S, Mayrhofer R, Schad I, El-Matbouli M, Focken U (2013) Improved sustainable aquaculture systems for small-scale farmers in northern Vietnam. In: Fröhlich HL, Schreinemachers P, Clemens G, Stahr K (eds) Sustainable land use and rural development in Southeast Asia: innovations and policies for mountainous areas. Springer Verlag, Berlin, p 281-317

Rodrigues EL, Fanta E (1998) Liver histopathology of the fish Brachydanio rerio Hamilton Buchmann after acute exposure to sublethal levels of the organophosphate Dimethoate 500. Rev Bras Zool 15:441-450

Sakai T, Murata H, Endo M, Shimomura T and others (1998) Severe oxidative stress is thought to be a principal cause of jaundice of yellowtail (Seriola quinqueradiata). Aquaculture 160:205-214

Steinbronn S (2009) A case study: fish production in the integrated farming system of the Black Thai in Yen Chau district (Son La province) in mountainous North-Western Vietnam - current state and potential. PhD thesis, University of Hohenheim, Stuttgart

Sturm A, Wogram J, Segner H, Liess M (2000) Different sensitivity of organophosphates of acetylcholinesterase and butyrylcholinesterase from three-spined stickleback 
(Gasterosteus aculeatus): application in biomonitoring. Environ Toxicol Chem 19:1607-1615

Sweilum MA (2006) Effect of sublethal toxicity of some pesticides on growth parameters, haematological properties and total production of Nile tilapia (Oreochromis niloticus L.) and water quality of ponds. Aquacult Res 37: 1079-1089

Takatori S, Okihashi M, Okamoto Y, Kitagawa Y and others (2008) A rapid and easy multiresidue method for the determination of pesticide residues in vegetables, fruits, and cereals using liquid chromatography/tandem mass spectrometry. J AOAC Int 91:871-883

Van PT, Khoa LV, Lua DT, Van KV, Ha NT (2002) The impacts of red spot disease on small-scale aquaculture in Northern Vietnam. In: Arthur JR, Phillips MJ, Subasinghe RP, Reantaso MB, MacRae IH (eds) Primary aquatic animal health care in rural, small-scale aquaculture development. FAO, Rome, p 165-176

Editorial responsibility: Thomas Braunbeck, Heidelberg, Germany
Wedemeyer GA (1972) Some physiological consequences of handling stress in the juvenile coho salmon (Oncorhynchus kisutch) and steelhead trout (Salmo gairdneri). J Fish Res Board Can 29:1780-1783

Weiss CM (1961) Physiological effect of organic phosphorus insecticides on several species of fish. Trans Am Fish Soc 90:143-152

WHO (World Health Organization) (2009) Inventory of IPCS and other WHO pesticide evaluations and summary of toxicological evaluations performed by the Joint Meeting on Pesticide Residues (JMPR) through 2009. Available at www.who.int/ipcs/publications/jmpr/pesticide_inventory_ edition10.pdf (accessed on 20 February 2013)

Wolf JC, Wolfe MJ (2005) A brief overview of nonneoplastic hepatic toxicity in fish. Toxicol Pathol 33:75-85

Xu W, Liu W, Shao X, Jiang G, Li X (2012) Effect of trichlorfon on hepatic lipid accumulation in crucian carp Carassius auratus gibelio. J Aquat Anim Health 24:185-194

Submitted: August 15, 2013; Accepted: December 17, 2013 Proofs received from author(s): February 11, 2014 